\title{
Acute anterior uveitis and Klebsiella aerogenes: a casual relationship?
}

\author{
H. E. WILLSHAW \\ From the Birmingham and Midland Eye Hospital, Church Street, Birmingham B3 2NS
}

SUMMARY This study was undertaken to investigate the hypothesis that episodes of anterior uveitis in patients with the HLA B27 antigen are triggered by the presence of Klebsiella aerogenes in the gastrointestinal tract. Forty patients were examined. While the recovery of klebsiella was greater in B27 positive patients with uveitis, the differences failed to reach statistical significance. The clinical state of patients with Klebsiella aerogenes in their faeces did not differ from that in whom klebsiella could not be recovered.

The major histocompatibility genes were first recognised in the mouse, where it was shown that loci in a certain region of the chromosome were responsible for antigen recognition and for defence against a number of artificial and naturally occurring antigens. ${ }^{\prime 2}$ The human equivalent of the $\mathrm{H} 2$ histocompatibility system in mice is the human lymphocytic antigen (HLA) system, a system of antigens which appear on the surface membranes of all body cells but are best identified on the surface of white cells.

Interest in this major histocompatibility complex stemmed from the recognition that a number of diseases appeared to show a positive or negative association with the presence of particular antigens. The significance of such associations must always be examined carefully, consideration being given to the frequency of the antigen in a 'normal' population as well as to racial and sex variations.

A number of disease entities are now established as having an HLA association, including coeliac disease with HLA B8, ${ }^{3}$ Behçet's disease with HLA B5, ${ }^{4}$ and others. However, far the closest association yet established is that between ankylosing spondylitis (AS) and possession of HLA B27,56 $96 \%$ of patients with AS being HLA B27 positive.

The mechanisms of disease association with HLA antigens is not firmly established, but the possibility of cross-reaction between the HLA antigen and antigens on an infecting micro-organism has been suggested.?

Cross-reactivity has been demonstrated between B27 positive lymphocytes and a number of enterobacteria, including Klebsiella aerogenes, ${ }^{8}$ and 2 Correspondence to $\mathrm{Mr} \mathrm{H}$. E. Willshaw. groups working independently appear to have shown an association between $K$. aerogenes in the faeces and acute uveitis in patients with AS. ${ }^{910}$

These results raised the question of whether $K$. aerogenes acts as a 'trigger' factor in HLA B27 positive patients who develop acute nongranulomatous anterior uveitis. The current study was designed to address this problem.

\section{Patients and methods}

Consecutive, unselected patients presenting to the Birmingham and Midland Eye Hospital with acute nongranulomatous anterior uveitis (ANGAU) were examined. In addition to routine assessment and investigation all were questioned about any history of back pain, peripheral joint pain, and gastrointestinal or skin disease. Any recent medication or hospitalisation was recorded, and all patients were asked to submit a faecal sample for bacteriological examination.

Blood was taken for tissue typing from all patients, and 26 HLA antigens were tested by the standard National Institute of Health microlymphocytoxic test. ${ }^{11}$

The patients' response to anti-inflammatory and mydriatic treatment was recorded, but no attempt was made to standardise therapy.

\section{Results}

Forty patients were included in the investigation. with one patient being examined during 2 separate episodes. Eighteen patients were excluded because of a lack of adequate bacteriology, and therefore 23 sets of results were available for analysis. 
Table 1 Recovery of Klebsiella aerogenes related to HLA B27 status

\begin{tabular}{lccl}
\hline & Klebsiella + ve & Klebsiella $-v e$ & Total \\
\hline B27 + ve & 6 & 14 & 10 \\
B27 - ve & 4 & 9 & 13 \\
Total & 10 & 13 & 23 \\
\hline
\end{tabular}

The age range of the patients was $15-73$ years, mean 39.6 years. Thirteen $(56.5 \%)$ were male, and no patient had any evidence of ankylosing spondylitis. Ten of the $23(43.5 \%)$ were HLA B27 positive, while in the total group of $40,18(45 \%)$ were HLA B27 positive. Of the $10 \mathrm{~B} 27$ positive patients $6(60 \%)$ were found to have $K$. aerogenes in their faeces. Among the 13 B27 negative patients only $4(30 \cdot 8 \%)$ had $K$. aerogenes in their faeces (Table 1).

No difference was found between the various groups in the patients' response to therapy.

\section{Discussion}

Firstly, these results confirm earlier findings ${ }^{1213}$ of an association between acute nongranulomatous anterior uveitis and possession of HLA B27, even in the absence of ankylosing spondylitis. That this apparent link between the 2 diseases might be genetically determined has attracted much attention and some of the work done ${ }^{14}$ strongly supports such a concept. Furthermore, good evidence has been provided to link episodes of acute uveitis in patients with ankylosing spondylitis to the presence of $K$. aerogenes in the faeces. ${ }^{1015}$

However, to invoke cross-reactivity and incriminate klebsiella as a trigger factor in uveitis generally, one would expect to see a similar pattern of recovery from the faeces of nonspondylitic patients with uveitis if they are HLA B27 positive. This has not proved to be the case. Though $K$. aerogenes was recovered more frequently from patients who were B27 positive, and the recovery rate from patients who were B27 negative did not exceed that expected from controls,${ }^{10}$ the differences failed to reach statistical significance $0 \cdot 1>p>0 \cdot 5$. (Similar work carried out between 1976 and $1979^{16}$ has also failed to show a statistically significant association.) Neither was there any difference in the clinical behaviour of the uveitis in B27 positive and B27 negative patients relating to the presence of $K$. aerogenes.

While there seems little doubt that a greater under- standing of uveal inflammation might be derived from further investigation of the role of HLA B27, there is no evidence in this study that traditional therapy needs to be modified according to the patient's B27 status, and the exact role of Klebsiella aerogenes in initiating episodes of uveitis also remains to be clarified.

I thank the Birmingham ophthalmologists for allowing me to examine their patients. Mr J. Lawson for performing the bacteriological examinations, and Dr P. Mackintosh for the HLA typing.

I also thank Mrs C. Rawlins for secretarial assistance.

\section{References}

1 Lilly F. Boyse EA. Old LJ. Genetic basis of susceptibility to viral leukaemogenesis. Lancet 1964: ii: 1207-9.

2 Nandi S. The histocompatibility - 2 locus and susceptibility to Bittner virus borne by red blood cells in mice. Proc Natl Acad Sci USA 1967; 58: 485-92.

3 Stokes PL. Asquith P. Holmes GKT. Mackintosh P. Cooke WT Histocompatibility antigens associated with adult coeliac disease. Lancet 1972: ii: 162-4.

4 Ohno S. Nakayama E. Seiji S. Katsuaki I. Koki A. Miki A. Specific histocompatibility antigens associated with Beçhet's disease. Am J Ophthalmol 1975; 80: 636-41.

5 Brewerton DA. Caffrey M. Hart FD. James DCO. Nicholls A. Sturrock RD. Ankylosing spondylitis and HL-A27. Lancet 1973: i: $904-7$.

6 Edmonds J, Morris R. Metzeger AL. et al. Follow up study of juvenile chronic polyarthritis with particular reference to histocompatibility antigen W27. Ann Rheum Dis 1974; 33: 289-92.

7 McDevitt HO. Bodmer WF. HLA immune response genes and disease. Lancet 1974: i: 1269-75.

8 Ebringer A. Cowling P. Ngwa SN, James DCO. Ebringer RW Cross reactivity between Klebsiella aerogenes species and B27 lymphocyte antigens and an aetiological factor in ankylosing spondylitis. In: Dausset J. Svejgaard A. HLA and Disease. Copenhagen: Munksgaard, 1976.

9 Ebringer R, Cooke D. Cawdell DR, Cowling P, Ebringer A. Ankylosing spondylitis: klebsiella and HLA B27. Rheumatol Rehabil 1977: 16: 190-6. or'.

10 Willshaw HE. Eastmond CJ. Role of environmental factors in uveitis. Trans Ophthalmol Soc UK 1979; 99: 160-2.

11 Batchelor JR. Identification of HL-A antigens by serological criteria. Ann Rheum Dis 1975: 34 suppl 1: 5-6.

12 Mapstone R. Woodrow JC. HL-A27 and acute anterior uveitis Br J Ophthalmol 1975; 59: 270-5.

13 Brewerton DA. HLA-A27 and acute anterior uveitis. Ann Rheum Dis 1975; 34 suppl 1: 33-5.

14 Eastmond CJ. Woodrow JC. Discordance for ankylosing spondylitis in monozygotic twins. Ann Rheum Dis 1977: 36: $360-4$.

15 Ebringer R. Cawdell D. Ebringer A. Klebsiella pneumoniae and acute anterior uveitis in ankvlosing spondvlitis. $B r \operatorname{Med} J$ 1979: i: 383.

16 Warren RE. Brewerton DA. Klebsiella, spondylitis and uveitis. Br Med J 1979; i: 889. 